\title{
SỬ DỰG PHƯƠNG PHÁP TỔNG QUÁT HÓA TỬ ĐộNG BÀ̀NG PHẦN MỀM FME ĐỂ NGHIÊN CÚU THÀNH LẬP BẢN ĐỒ HIỆN TRẠNG SỬ DỤNG ĐẤT CẤP HUYỆN TỬ CƠ SỞ DỮ LIỆU ĐỊA CHÍNH CẤP XÃ
}

\author{
ThS. BÙI TH!̣ CẨM NGỌC(1), ThS. NGUYẼN TH!̣ CHI ${ }^{(1)}$, ThS. VŨ LẸ HÀ(2) \\ (1) Viện Khoa học Đo đạc và Bản đồ \\ (2)Trường Đại học Tài nguyên và Môi trường Hà Nội
}

\section{Tóm tắt:}

Quản lý đất đai luôn là vấn đề đã và đang được quan tâm đặc biệt ở bất kỳ một quốc gia nào trên thế giới. Việt Nam đang trong giai đoạn ưu tiên phát triển kinh tế - xã hội, công tác quản lý đất đai luôn giữ vai trò hết sức quan trọng. Bản đồ hiện trạng sử dụng đất là tài liệu không thể thiếu trong công tác quản lý nhà nước về đất đai, đặc biệt là trong thống kê, kiểm kê, lập quy hoạch sử dụng đất,... Việc tự động xây dụ̂ng bản đồ hiện trạng sử dụng đất từ cơ sở dư liệu địa chính đang ngày càng được quan tâm. Vì vậy, sử dụng phương pháp tổng quát hóa tự động bằng phần mềm FME để nghiên cứu thành lập bản đồ hiện trạng sử dụng đất cấp huyện từ cơ sở dư liệu địa chính cấp xã là một hướng nghiên cứu có tính thực tiễn cao.

\section{Mở đầu}

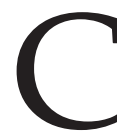

ông nghệ thông tin đã và đang phát triển mạnh mẽ, thâm nhập hầu hết các ngành khoa học, các hoạt động thực tiễn và nghiên cứu. Các thành tựu khoa học kỹ thuật tiên tiến của công nghệ điện tử, viễn thông và tin học đã tạo ra những bước đột phá mới trong công nghệ viễn thám và các phần mềm mới ứng dụng cho GIS. Vì vây, việc sử dụng công nghệ mới, ứng dụng các phần mới trong công tác thành lập bản đồ HTSDĐ là rất cần thiết cho công tác quản lý đất đai.

Hiện nay, Tổng cục Quản lý đất đai đã xây dựng chuẩn cơ sở dữ liệu địa chính theo mô hình cơ sở dữ liệu hướng đối tượng với mục tiêu đồng bộ và thống nhất dữ liệu. Cơ sở dữ liệu địa chính là dữ liệu nền để xây dựng cơ sở dữ liệu về hiện trạng, quy hoạch sử dụng đất, về giá đất và các cơ sở dữ liệu thành phần khác. Cơ sở dữ liệu địa chính phải đáp ứng các tiêu chuẩn kỹ thuật, các quy trình, quy định phải tuân thủ các văn bản quy phạm pháp luật về lĩnh vực đất đai, được quản lý trên nền công nghệ hiện đại, đảm bảo an ninh, an toàn dữ liệu có độ tin cậy cao, cung cấp thông tin chính xác và kịp thời cho công tác quản lý nhà nước về đất đai có hiệu quản, thực hiện mục tiêu kinh tế hóa ngành tài nguyên và môi trường nói chung và trong hoạt động quản lý đất đai nói riêng. Việc xây dựng bản đồ hiện trạng sử dụng đất từ chuẩn cơ sở dữ liệu địa chính là một nhu cầu cần thiết, các thông tin trong chuẩn dữ liệu địa chính cung cấp đầy đủ thông tin để có thể thành lập tự động bản đồ hiện trạng sử dụng đất các cấp.

2. Cơ sơ khoa học thành lập bản đồ hiện trạng sử dụng đất tư cơ sơ dữ liệu địa chính bằng phương pháp tổng quát hóa

2.1. Một số vấn đề về tổng quát hóa bản đồ và tổng quát hóa dữ liệu 
Tổng quát hoá bản đồ là phương pháp đặc biệt để lựa chọn và khái quát các yếu tố nội dung bản đồ, làm sáng tỏ và biểu thị lên bản đồ các đặc điểm đặc trưng, những nét cơ bản, điển hình của đối tượng, hiện tượng và mối tương tác giữa chúng với nhau. Đồng thời tổng quát hoá cũng làm nổi bật các qui luật tự nhiên và kinh tế xã hội.

\section{Tổng quát hóa tự động}

Trong quá trình thành lập bản đồ, tổng quát hóa là công việc rất quan trọng bảo đảm cho bản đồ có nội dung đầy đủ nhất, tốt nhất với các thông tin cần thiết cho mục đích nghiên cứu lãnh thổ.

\section{- Tổng quát hóa dữ liệu Vector}

Quá trình tổng quát hoá được đưa ra bởi Shea và McMaster năm 1989, đã đưa ra 12 hoạt động tổng quát hoá gây ảnh hưởng lớn đến sự phát triển của các phần mềm tổng quát hoá trong suốt những năm 90 đó là:

+ Simplification (Đơn giản hóa), Smoothing (Làm trơn đối tượng), Amalgamation (Gộp vùng), Aggregation (Kết hợp dạng điểm), Merging (Kết hợp dạng đường), Collepse, Selection (Sự lựa chọn), Exaggeration (Phóng đại), Enhancement (Phóng đại), Displacement (Chuyển dịch), Classification (Sự phân loại), Symbolisation.

\section{- Tổng quát hóa dữ liệu raster}

Tổng quát hoá các dữ liệu raster phù hợp cho cách trình bày dữ liệu thể hiện trực tiếp trong định dạng raster, tổng quát hoá raster thường sử dụng cho các loại bản đồ hiện trạng sử dụng đất hoặc các dữ liệu phủ trùm trên mặt đất có thể giải đoán dựa trên sự hiển thị của chúng trên ảnh vệ tinh. Các phương pháp cơ bản cho tổng quát hoá dữ liệu raster bao gồm: Sự đơn giản hoá, loại bỏ các vùng nhỏ, làm trơn các đường bao vùng và hợp nhất các bề mặt.

\subsection{Nội dung và cấu trúc chuẩn co' sở dữ liệu địia chính}

Theo thông tư 17/2010/TT_BTNMT của Bộ Tài Nguyên và Môi Trường ngày 04 tháng 10 năm 2010 quy định về chuẩn dữ liệu địa chính bao gồm:

- Chuẩn về nội dung cấu trúc, kiểu thông tin của dữ liệu địa chính;

- Hệ quy chiếu không gian và thời gian của dữ liệu địa chính;

- Siêu dũ liệu địa chính;

- Chất lượng dữ liệu địa chính;

- Trình bày và hiển thị dữ liệu địa chính;

- Trao đổi, phân phối dữ liệu và siêu dữ liệu địa chính; (Xem hình 1)

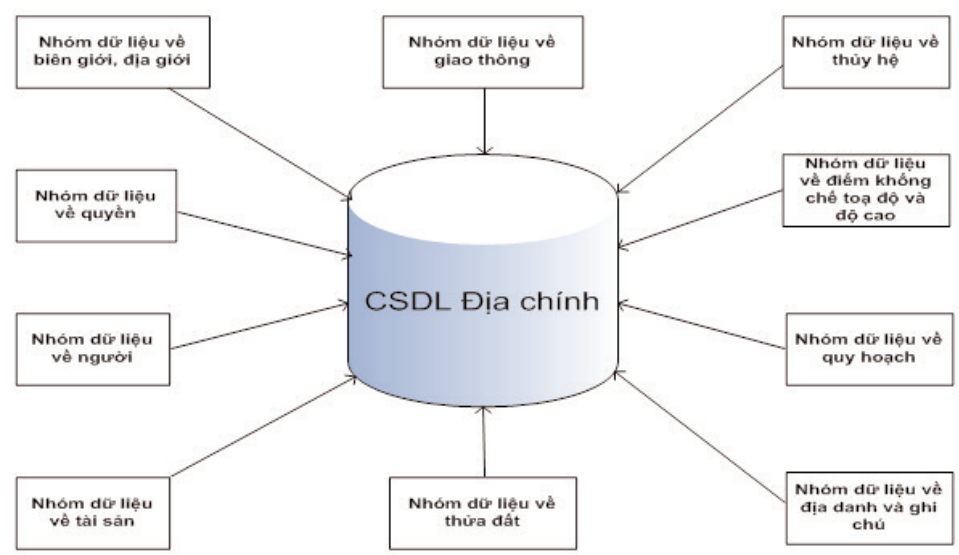

Hình 1: Các nhóm dữ liệu cấu thành nên cơ sở dữ liệu địa chính 


\subsection{Tổng quan về phần mềm $\mathrm{FME}$}

Giới thiệu một số công cư có chức năng tổng quát hóa của phần mềm FME

FME là phần mềm đứng đầu thế giới về chuyển đổi định dạng dữ liệu. Chúng được sử dụng rộng rãi bởi các tổ chức cần truy nhập, thao tác các loại dữ liệu GIS, CAD và nhiều định dạng dư liệu khác. FME bao gồm 3 thành phần chính: $\mathrm{FME}$ Universal Translator, FME WorkBench và FME Universal Viewer.
Một số công cụ có chức năng tổng quát hóa của phần mềm FME gồm có

$$
\text { - Dissolves (Gộp vùng), }
$$

AreaFillColorSetter (Tô màu cho đối tượng vùng), DGNStyler- LineGeneralizer (Tổng quát hoá các đối tượng dạng đường),...

3. Xây dựng quy trình thành lập $B \oplus$ HTSDĐ bằng phương pháp tổng quát hoá từ cơ sở dữ liệu địa chính. (Xem hình 2)

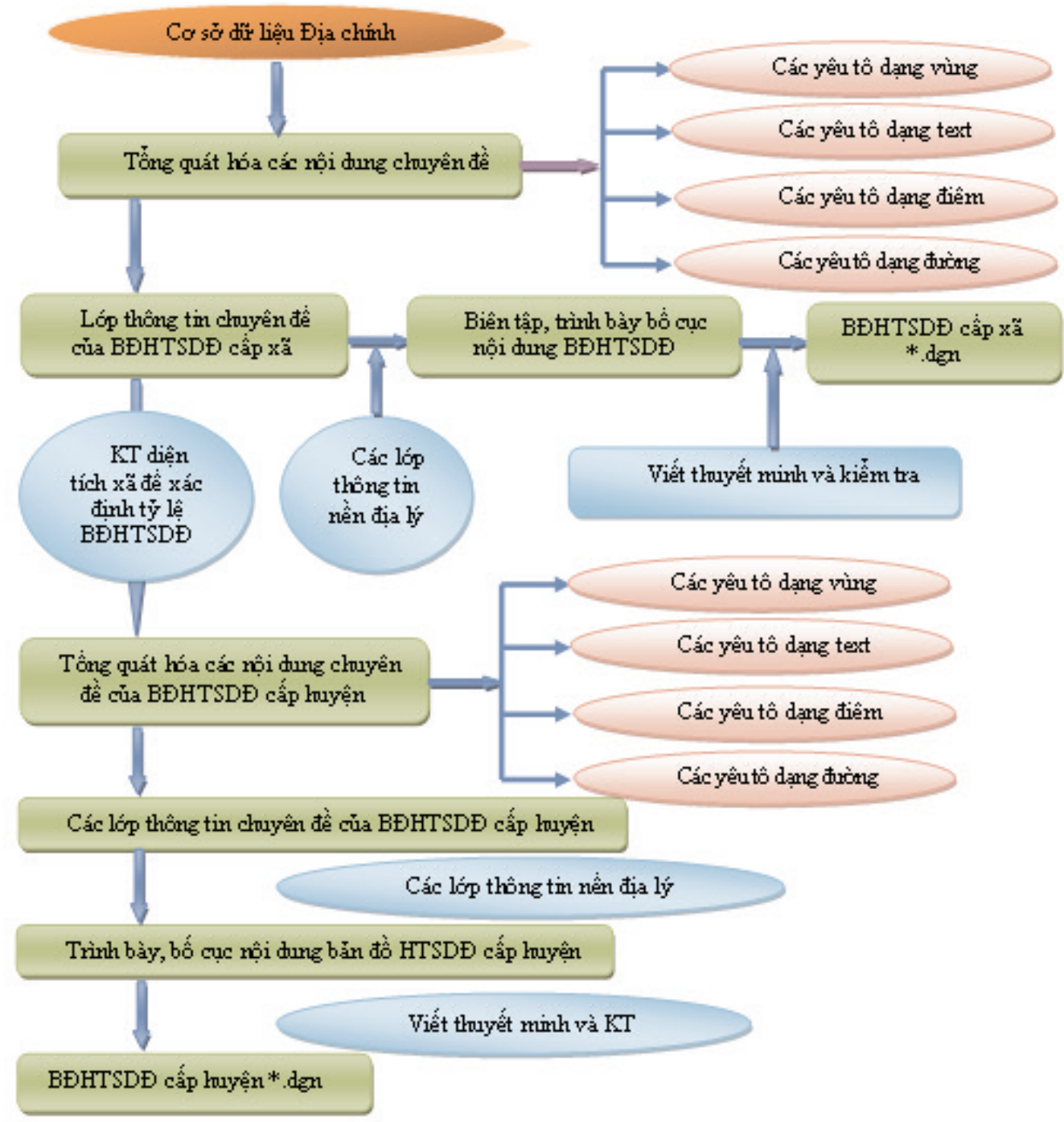

Hình 2: Quy trình thành lập bản đồ hiện trạng sử dụng đất bằng phương pháp tổng quát hoá từ cơ sở dữ liệu địa chính 
4. Thử nghiệm thành lập bản đồ hiện trạng sử dụng đất cấp huyện tư co' sơ dữ liệu địa chính tại huyện Bình Minh, tỉnh Vinh Long

Huyện Bình Minh có vị trí địa lý nằm ở về phía tây bắc tỉnh Vĩnh Long, tiếp giáp với tỉnh Đồng Tháp. Thực hiện theo Quyết định số 125/2007/NĐ-CP ngày 31/7/2007 của Thủ tướng Chính phủ về việc thành lập huyện Bình Tân trên cơ sở điều chỉnh địa giới hành chính huyện Bình Minh, tỉnh Vĩnh Long. Sau khi chia tách 11 xã: Mỹ Thuận, Nguyễn Văn Thảnh, Thành Lợi, Thành Đông, Thành Trung, Tân Quới, Tân Bình, Tân Thành, Tân Hưng, Tân Lược và Tân An Thạnh về huyện Bình Tân. Huyện Bình Minh chỉ còn lại 5 xã 1 thị trấn, bao gồm: Xã Đông Bình, Đông Thành, Đông Thạnh, Mỹ Hoà, Thuận An và Thị trấn Cái Vồn, với tổng diện tích tự nhiên 9.337,12 ha.

\subsection{Thử nghiệm thành lập bản đồ sử dụng đất cấp xã}

Sau khi dữ liệu được chuẩn hoá và đưa vào cơ sở dữ liệu (CSDLDC.MDB), nhóm tác giả đã tiến hành xây dựng modul tổng quát hoá thành lập bản đồ hiện trạng sử dụng đất cấp xã từ cơ sở dữ liệu địa chính.

Trong quá trình xây dựng modul nhóm tác giả đã sử dụng một số công cụ tổng quát hoá như sau: LineGeneralized, AreaGeneralized, Dissolve, AttributeFilter, AreaFillColorSetter,...

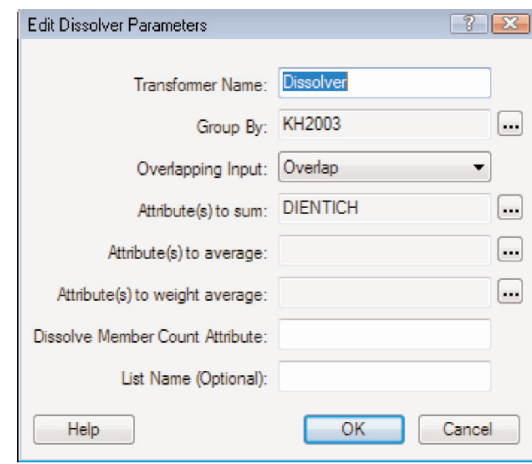

Hình 3: Các thông số lựa chọn cho hàm Dissolve
Các hàm này được kết hợp linh hoạt để thiết kế dữ liệu vào các lớp theo quy định của bản đồ hiện trạng.

Modul bản đồ hiện trạng sử dụng đất cấp xã từ cơ sở dữ liệu địa chính

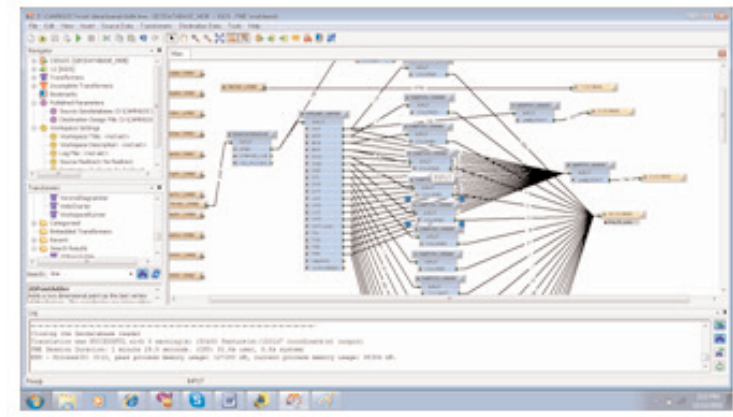

Hình 4: Modul thành lập bản đồ hiện trạng cấp xã

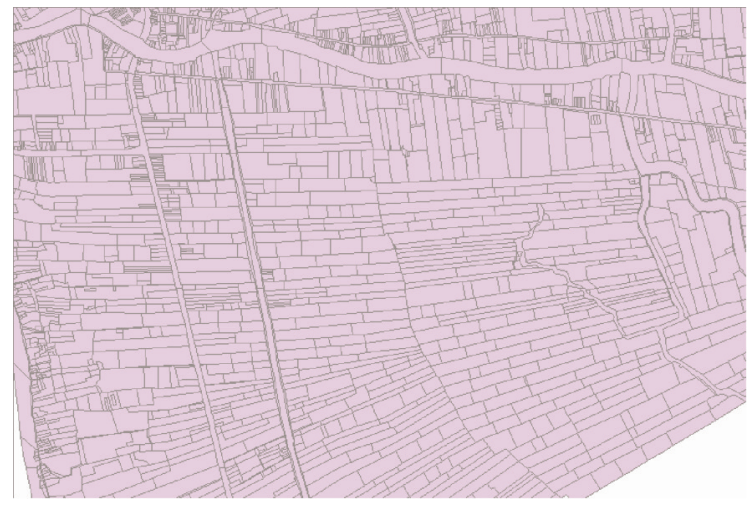

Hình 5: Cơ sở dũ̃ liệu địa chính sau khi đã chuẩn hoá

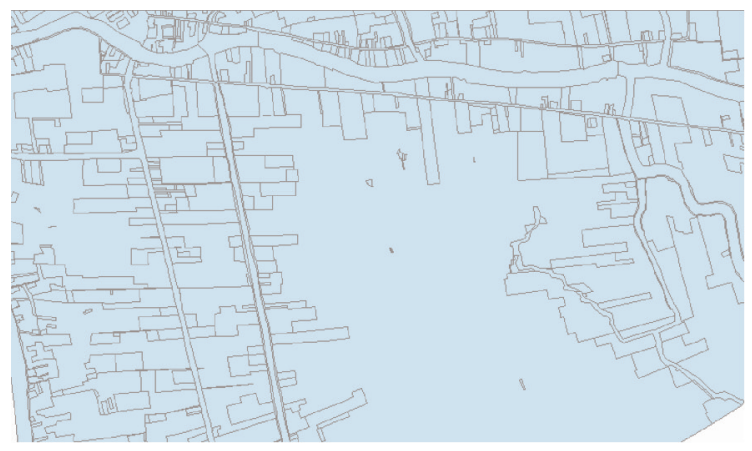

Hình 6: Dũ liệu cấp xã sau khi đã tổng quát hoá các thửa có cùng loại đất 
Sau khi chạy tự động modul thành lập bản đồ hiện trạng sử dụng đất cấp xã, sản phẩm thu được như sau:

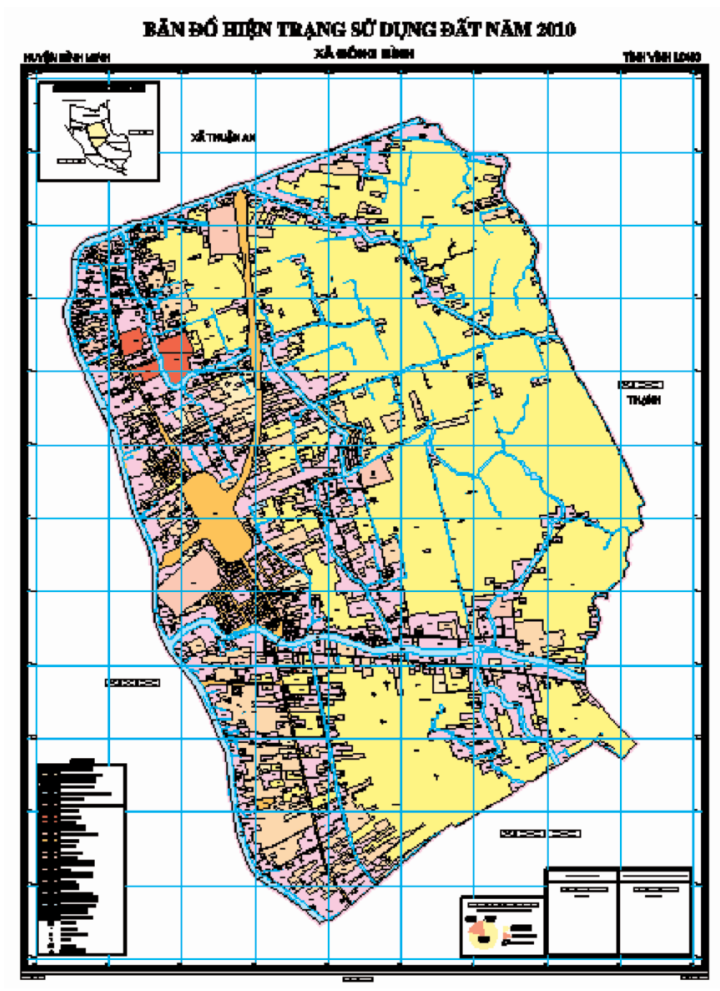

Hình 7: Bản đồ hiện trạng sử dụng đất cấp xã sau khi biên tập

\subsection{Thử nghiệm thành lập bản đồ hiện trạng cấp huyện}

Từ cơ sở dữ liệu hiện trạng cấp xã, thực hiện tổng quát hoá lên bản đồ hiện trạng sử dụng đất cấp huyện. Một số công cụ thường dùng trong modul tự động thành lập bản đồ hiện trạng sử dụng đất cấp huyện như: LineGeneralized, AreaGeneralized, Dissolve, AttributeFilter, AreaFillColorSetter, Tester,....

Thông số lựa chọn một số hàm trong modul thành lập bản đồ hiện trạng sử dụng đất cấp huyện như sau:

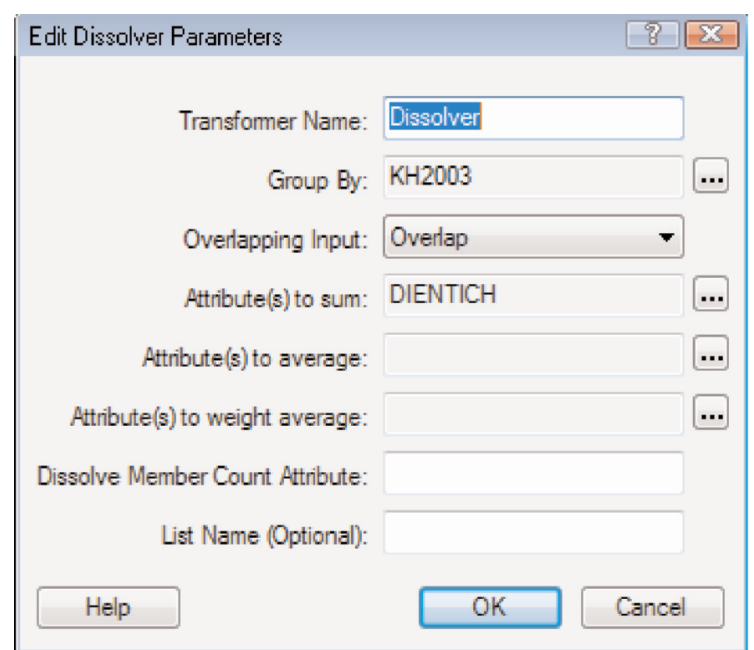

Hình 8: Thông số hàm Dissolve

- Thông số lựa chọn của hàm Tester: Lựa chọn các vùng có diện tích >= $1600 \mathrm{~m}^{2}$ để giữ lại. Các vùng có diện tích bé thì gộp vào vùng có diện tích lớn hơn liền kề.

Modul thành lập bản đồ hiện trạng sử dụng đất cấp huyện

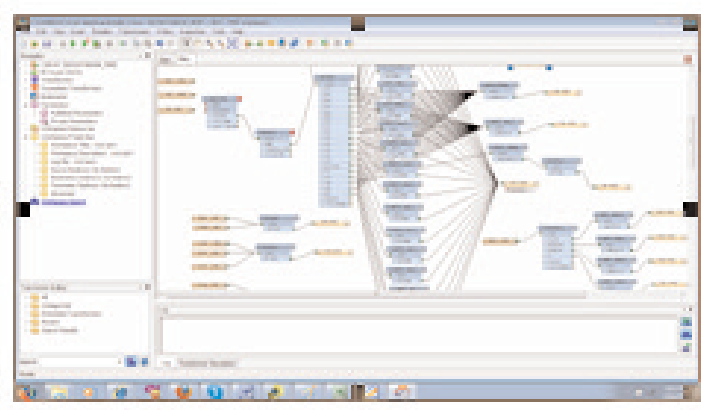

Hình 9: Modul thành lập bản đồ hiện trạng sử dụng đất cấp huyện

Sau khi chạy tự động bản đồ hiện trạng sử dụng đất cấp huyện thu được như sau: 


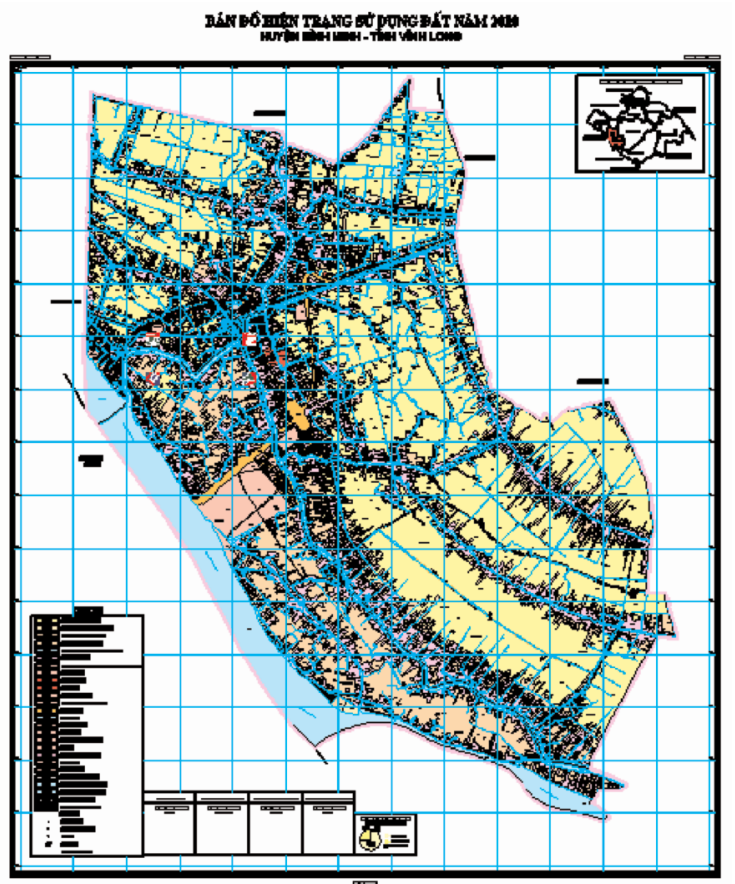

Hình 10: Bản đồ hiện trạng sử dụng đất cấp huyện sau khi biên tập

\section{3. Đánh giá kết quả thử nghiệm} đồ

4.3.1. Đánh giá về độ chính xác của bản

\section{a. Độ chính xác không gian}

- Bản đồ thử nghiệm so với các bản đồ hiện trạng sử dụng đất thực hiện bằng phương pháp truyền thống có độ chính xác cao hơn. Do nguồn dữ liệu đầu vào là CSDL địa chính (phần dữ liệu không gian là bản đồ địa chính). Đây là loại bản đồ tỷ lệ lớn, có tính pháp lý, thống nhất và có độ chính xác cao.

- Qua quá trình thử nghiệm, nhóm tác giả đánh giá về mặt diện tích các thửa đất không có biến đổi nhiều, các khoanh đất của bản đồ thử nghiệm có ranh giới trùng khớp với dữ liệu thửa đất trong cơ sở dữ liệu địa chính.

\section{b. Độ chính xác thuộc tính}

- Nội dung của cơ sở dữ liệu địa chính đầy đủ, chính xác và phù hợp để thành lập bản đồ hiện trạng sử dụng đất các cấp.

- Việc ra chuẩn cơ sở dữ liệu địa chính tạo điều kiện thống nhất tất cả các thông tin, tránh tình trạng chồng chéo, không chính xác, không đồng bộ trong việc khai thác thông tin cơ sở.

- Nội dung thông tin cơ sở dữ liệu địa chính cụ thể, chi tiết, đáp ứng được yều cầu xây dựng quy trình tự động hóa thành lập bản đồ hiện trạng sử dụng đất các cấp. Từ nội dung này có thể thành lập lên bản đồ hiện trạng sử dụng đất cấp huyện với đầy đủ thông tin chuyên đề theo yêu cầu.

- Các trường thuộc tính trong cơ sở dư liệu địa chính đơn giản phù hợp để tự động hóa truy vấn và tạo kí hiệu các loại đất trong bản đồ hiện trạng sử dụng đất cấp huyện

4.3.2. Đánh giá modul thành lập bản đồ hiện trạng sử dụng đất cấp huyện từ cơ sở dữ liệu địa chính bằng phần mềm FME

Modul thành lập bản đồ hiện trạng sử dụng đất cấp xã và cấp huyện tạo ra sản phẩm có định dạng *.dgn theo đúng quy định của Bộ Tài nguyên và Môi trường và tạo điều kiện thuận lợi để chuyển sang các định dạng khác.

Modul được thành lập đơn giản, dễ sử dụng, chạy trên nền ứng dụng của phần mềm FME nên thuận tiện trong việc sử dụng trực tiếp các công cụ của phần mềm FME, giúp người sử dụng dễ dàng thao tác.

Modul tạo ra có khả năng chạy tự động tốt, đáp ứng được các quy định kỹ thuật của bản đồ hiện trạng sử dụng đất do Bộ Tài nguyên và Môi trường ban hành. Tuy nhiên modul vẫn còn một số nhược điểm như: không tiện lợi trong kiểm tra và sửa lỗi, xử lý không triệt để các trường hợp các đối tượng có số lượng lớn hoặc có yêu cầu về tổng quát hoá mạng lưới. 


\section{Kết luận}

Kết quả nghiên cưu cho thấy rằng: sử dụng phương pháp tổng quát hóa tự động và phần mềm FME đã thành lập được bản đồ hiện trạng sử dụng đất cấp huyện có độ chính xác cao, nhanh chóng, thuận tiện, phù hợp với các yêu cầu kỹ thuật về bản đồ hiện trạng sư dụng đất của Bộ Tài nguyên và Môi trương.

Modul tạo ra có khả năng chạy ổn định, đơn giản, phủ hợp với trình độ của cán bộ quản lý.

Qua quá trình thực hiện nhận thấy quy trinh đề xuất về việc thành lập tự động bản đồ hiện trạng sử dụng đất cấp huyện là một quy trình đơn giản, dễ áp dụng vào thực tế sản xuất, tiết kiệm thời gian, kinh phí thực hiện và đạt được độ chính xác cao. $\bigcirc$

\section{Tài liệu tham khảo}

[1]. Quy định về thành lập bản đồ hiện trạng sử dụng đất năm 2007 (QĐ số 22/2007/QĐ - BTNMT ngày 17/12/2007 của Bộ trưởng Bộ Tài nguyên và Môi trường).
[2]. Bộ Kí hiệu Bản đồ hiện trạng sử dụng đất và bản đồ quy hoạch sử dụng đất tỷ lệ $1: 1.000, \quad 1: 2.000, \quad 1: 5.000, \quad 1: 10.000$, $1: 25.000,1: 50.000,1: 100.000,1: 250.000$, 1:1.000.000 (QĐ số 23/2007/QĐ - BTNMT ngày 17/12/2007 của Bộ trưởng Bộ Tài nguyên và Môi trường).

[3]. Thông tư 17/2010/TT - BTNMT ngày 4 tháng 10 năm 2010 quy định kỹ thuật về chuẩn dữ liệu địa chính.

[4]. Hướng dẫn sử dụng phần mềm FME.

[5]. Báo cáo hiện trạng sử dụng đất năm 2010 tỉnh Vĩnh Long, Sở Tài nguyên và Môi trường tỉnh Vĩnh Long.

[6]. Đồng Thị Bích Phương, Đề tài NCKH cấp Bộ, Nghiên cứu cơ sở khoa học tổng quát hóa tự động và xây dựng phần mềm tổng quát hóa bản đồ từ dữ liệu bản đồ địa hình tỷ lệ lớn hơn, Viện Khoa học Đo đạc và Bản đồ.

[7]. Vũ Xuân Cường (2009), Tự động thành lập bản đồ hiện trạng sử dụng đất. $\bigcirc$

\section{Summary}

USING GENERALIZED METHOD OF AUTOMATIC FME SOFTWARE FOR RESEARCH INTO MAPPING THE DISTRICT-LEVEL LAND USE FROM DATABASE CADASTRAL COMMUNE-LEVEL

\section{MSc. Bui Thi Cam Ngoc, MSc. Nguyen Thi Chi - Institute of Geodesy and Cartography}

\section{MSc. Vu Le Ha - Hanoi University of Natutal Resources and Environment}

Land management issues have always been particularly interested in any other country in the world. Vietnam is in the process of economic development priorities - social, land management keeps very important role. A map of the land use is an indispensable material in the management of state land, especially in statistics, inventory, land use planning, building automation... The map is from land use database administration is increasingly concerned. So, using generalized method of automatic FME software to study the current state mapping land use district database from communal land is a research oriented practical. $\mathrm{O}$

Ngày nhận bài 20/5/2013. 